\title{
Drug use Pattern and Antenatal Care Utilization Among Pregnant Women in Ethiopia
}

Getahun Asmamaw ( $\square$ getahun.asmamaw@amu.edu.et )

Arba Minch University

Wondim Ayenew

University Of Gondar

Dinksew Tewuhibo

Madda Walabu University

\section{Research Article}

Keywords: Pregnancy, Drug use, Antenatal care, Determinants, Ethiopia

Posted Date: December 9th, 2020

DOI: https://doi.org/10.21203/rs.3.rs-117318/v1

License: (1) This work is licensed under a Creative Commons Attribution 4.0 International License.

Read Full License 


\section{Abstract}

Background: Taking medications during pregnancy can harm both the mother and fetus. However, avoiding drug utilization is a difficult due chance to occur maternal complications. The irrational use of medicine remains to worsen in developing countries. The main objective of this study was to evaluate the medication use pattern and its determinants among pregnant women in Ethiopia.

Methods: This study used the national representative secondary data obtained from the 2016 Ethiopian Demographic health survey (DHSprogram.com/Data). Simple descriptive statistics were used to present the socio-economic characteristics of the respondents. Bivariate and multivariate regression models were performed consecutively to examine the significant statistical association between medication use and independent variables. Variables $p<0.25$ during bivariate analysis were further analyzed with a multivariate regression model. A significant statistical association was detected if $p<0.05$ at $95 \%$ confidence interval $(\mathrm{Cl})$. The $95 \% \mathrm{Cls}$ and Odds ratios (OR) were also calculated for significant variables in bivariate regression. Stata/SE 14.2 statistical software was used to analyze the data.

Results: About 10,29 (91.8\%) of surveyed pregnant had taken at least one prescription drug. Thus, supplementary drugs were dominant (34\% of iron folate). The prevalence of non supplementary drugs such as anthelmintic $(15.3 \%)$, antibiotics $(6 \%)$ followed by antimalarial $(1.7 \%)$ drugs. Less than half 380 (34\%) pregnant had received antenatal care (ANC) during their pregnancy. Thus, the majority of 364 (96\%) of them received the ANC service at public health sectors. Most pregnant were in the second trimester when they started ANC. Pregnant aged from 35-49 years used drugs less likely by $65 \%(\mathrm{OR}=$ $0.35,95 \% \mathrm{Cl}=0.069-1.772$ ) compared to younger pregnant. Poorer mothers were more likely to take medications by $53 \%(\mathrm{OR}=0.47,95 \% \mathrm{Cl}=0.218-1.628)$ than middle income. The majority of pregnant were used medication during the second trimester (39.3\%) followed by the third trimester (38.5\%).

Conclusion: The utilization of ANC was lower among pregnant women. Hence, increasing the coverage and utilization of ANC services is needed to improve the consumption of supplements and other preventive chemotherapy. Likewise, to expand the ANC service channel is important to monitor the irrational drug use of pregnant.

\section{Introduction}

Drug utilization during pregnancy imposes a challenge in providing healthcare services for pregnant women [1-2]. Taking medications during this period is related to adverse effects for both the mother and fetus [3]. The concern for drug utilization for pregnant women has been given after the teratogenic incidence of thalidomide and diethylstilbestrol in the 1960s and 1971 respectively [4]. The presence of the undesired effects of drugs is a result of the wide range of changes in physiological, pharmacokinetic, and physiological functions of pregnant women [5-7]. Enough information for the danger of all available medicines during pregnancy is not available yet. Even though, several reports from studied drugs are recommended not to take medications during periods of pregnancy, while using some medicines with 
caution is allowed. Reports from both developed and undeveloped countries revealed 1.5 to $4.5 \%$ of pregnant women had used harmful drugs [8]. Furthermore, about $20 \%$ of women purchase at least one contraindicated drug during their pregnancy period [9]. Likewise, minimum of one prescription drug had utilized by around $86 \%$ of pregnant [10].

Limited studies in Ethiopia had been also illustrated significant findings regarding the utilization of medications in pregnancy. Thus, studies in Addis Ababa (71\%), Bahr Dar (88\%), Nekemte (96\%), Adigrat (88\%), and Harar (85\%) of pregnant women had reported a history of medicine use [11-15]. A study in Adama revealed an average of $1.7 \pm 6$ drugs per encounter [16]. Irrational use of drugs in pregnancy can be worsened in developing countries including Ethiopia. The lack of information, lower educational level, poor health-seeking behavior, and late or not initiation of antenatal care (ANC) are factors from the mother's side [13]. Moreover, lack of updated drug information among healthcare professionals, lack of standard of prescribing guidelines in the country are also additional challenges from the government perspective [13]. ANC during pregnancy could minimize the irrational use of the drug among pregnant women in the context of our country. WHO recommends at least four ANC follow up during pregnancy periods [17], [18]. Health care follows up during pregnancy is key for the mother and child's wellbeing. Ethiopian Government has given attention to antenatal (ANC) of pregnant women. The maternal and child care priorities have been highlighted in the 2015/16 Health Sector Transformation Plan (HSTP) document [17].

There is no enough information on-trend of drug use pattern among pregnant who utilizes ANC service in Ethiopia. This is important to inform policymaker in improving the effectiveness of maternal health care. Hence, to know the protectiveness of ANC for irrational drug use in pregnancy needed to be assessed at a national level.

\section{Methods}

\section{Data source}

The data analyzed by a recent study was obtained from the 2016 EDHS (DHSprogram.com/Data) conducted by the Ethiopian Central Statistical Agency (ECSA). EDHS 2016 is a nationally representative survey to provide updated information on demographic and health characteristics of households in the country [19]. The standard questionnaire has consisted of five main streams illustrated as households, women's health, men's health, biomarkers, and health facilities. The sampling design of the survey has two levels of strata (urban and rural areas), and samples were selected in two stages. In total, 15,683 women were interviewed. Further detailed information concerning maternal health and household characteristics was described in the 2016 EDHS report [19]. The dataset was obtained after permission from ICF international's DHS program office in Rockville, USA.

\section{Study variables}




\section{Dependent variable}

The main objective of this study was to evaluate the medication use pattern and associated factors among pregnant women in Ethiopia. According to the current study context, a drug utilization pattern is defined as taking medications and vaccines for any medical condition or the prevention of any disease during the pregnancy period. The national DHS 2016 survey has asked pregnant women about the category of drug used during pregnancy, the source, and the reason to use. The source of medication is also defined as the area of the health facility where the drug was obtained or purchased.

\section{Independent variables}

Socio-economic characteristics such as age, marital status, educational level, employment status, wealth level, area of residence was identified as independent variables. Moreover, pregnancy status such as gravidity, last birth, plan of pregnancy were also independent variables in this study. The DHS 2016 survey category was used for each variable. Likewise, utilizing ANC was added as an additional independent variable since receiving antenatal care services can influence the medication use by pregnant women [13]. Other variables were associated with delivering ANC (health facility, frequency of visits, provider educational status, and pregnancy month of starting ANC) were also considered. ANC providers were classified as "skilled providers" when the service is delivered with doctors, nurse/midwives, health officers, and health extension workers [19].

\section{Statistical analysis}

Pregnant women who took medicines during pregnancy were categorized by pharmacological classifications. Socio-economic characteristics of participants were summarized by simple descriptive statistics such as frequency, average, and percentages are presented by tables and figures. Inferential statistics were also used to examine the significant association between medication use and independent variables including antenatal care. First, a bivariate regression analysis model was performed, and then those variables $<0.25 p$-value were further analyzed with multivariate analysis. A significant statistical association was stated when the $\mathrm{p}$-value is $<0.05$ at a $95 \%$ confidence interval ( $\mathrm{Cl}$ ). $95 \%$ confidence intervals and odds ratios (OR) were also estimated for some selected variables. The obtained data were analyzed using Stata/SE 14.2 statistical software.

\section{Results}

\section{Socio-economic characteristics}

Around 1,122 pregnant women were pregnant during the EDHS 2016 survey, thus $91 \%$ of them were aged from 20 to 49 years (Table 1$)$. The majority $(96.6 \%)$ of pregnant were married and currently living with their husband. More than half (53.2\%) of pregnant were illiterates and $55.2 \%$ of them were unemployed. Only $12 \%$ had completed secondary and above school. Moreover, nearly $85.8 \%$ of pregnant women have resided in a rural area and $65 \%$ had middle to poorest income. 
Table 1

Selected background characteristics of pregnant women age 15-49, EDHS 2016

\begin{tabular}{|c|c|c|}
\hline Respondent characteristics & $\mathbf{n}$ & $(\%)$ \\
\hline Total sample & 1,122 & $(100)$ \\
\hline \multicolumn{3}{|l|}{ Age (years) } \\
\hline $15-19$ & 100 & $(8.9)$ \\
\hline $20-34$ & 845 & $(75.3)$ \\
\hline $35-49$ & 177 & $(15.8)$ \\
\hline \multicolumn{3}{|l|}{ Marital status } \\
\hline Never married & 10 & $(0.9)$ \\
\hline Married or living together & 1084 & $(96.6)$ \\
\hline Divorced/Separated/Widowed & 28 & $(2.5)$ \\
\hline \multicolumn{3}{|l|}{ Education level } \\
\hline No education & 597 & $(53.2)$ \\
\hline Primary education & 393 & $(35.0)$ \\
\hline Secondary education & 93 & $(8.3)$ \\
\hline More than secondary education & 39 & $(3.5)$ \\
\hline \multicolumn{3}{|l|}{ Employment status } \\
\hline Unemployed & 619 & $(55.2)$ \\
\hline Employed & 503 & $(44.9)$ \\
\hline \multicolumn{3}{|l|}{ Residence } \\
\hline Urban & 159 & $(14.2)$ \\
\hline Rural & 963 & $(85.8)$ \\
\hline \multicolumn{3}{|l|}{ Wealth status } \\
\hline Poorest & 254 & $(22.7)$ \\
\hline Poorer & 262 & $(23.3)$ \\
\hline Middle & 211 & (18.8) \\
\hline Richer & 196 & (17.5) \\
\hline Richest & 199 & (17.8) \\
\hline
\end{tabular}




\section{Pregnancy status of respondents}

The majority of women had conceived as they planned, while nearly $10 \%$ of them never accepted the current pregnancy yet (Table 2). Around $67 \%$ of pregnant women were in their second and third trimesters. Concerning the history of giving birth, $95 \%$ of them had not birthed in the year before the survey. Likewise, about $68 \%$ had more than one birth in the last five years.

Table 2

Pregnancy status characteristics of respondent women age 15-49, EDHS 2016

\begin{tabular}{|lll|}
\hline Pregnancy status & $\mathbf{n}$ & (\%) \\
\hline Plan of pregnancy & & \\
\hline Needed & 789 & $(70.3)$ \\
\hline Accepted later & 227 & $(20.3)$ \\
\hline Never accepted & 105 & $(9.4)$ \\
\hline Trimester & & \\
\hline First trimester & 241 & $(21.5)$ \\
\hline Second trimester & 441 & $(39.3)$ \\
\hline Third trimester & 441 & $(39.3)$ \\
\hline Births in the past year & & \\
\hline No births & 1,085 & $(95.6)$ \\
\hline 1 & 50 & $(4.4)$ \\
\hline 2 & 31 & $(0.08)$ \\
\hline Births in the last five years & & \\
\hline No births & 366 & $(32)$ \\
\hline 1 & 501 & $(44)$ \\
\hline 2 & 234 & $(21)$ \\
\hline 3 & 32 & $(2.8)$ \\
\hline 4 & 2 & $(0.2)$ \\
\hline
\end{tabular}

\section{Obstetric utilization characteristics}


Of 1,122 pregnant women, less than half $380(34 \%)$ had received antenatal care during their pregnancy period. The majority $364(95.8 \%)$ of them gained their antenatal care at the government health sector, the professional health caregiver had provided for $216(27.7 \%)$ of them (Table 3). Thus, nearly half $199(48 \%)$ of pregnant women were in their third trimester when they first started antenatal care service. However, there was a decrease in the number of pregnant visiting healthcare sectors for antenatal care during third trimester. Concerning the frequency of visits for the antenatal checks, a remarkable number of $350(85 \%)$ of them visited less than six times during their pregnancy period. 
Table 3

Antenatal care utilization among pregnant women age 15-49, Ethiopia DHS 2016

\begin{tabular}{|c|c|c|}
\hline & $\mathbf{n}$ & $(\%)$ \\
\hline Receive antenatal care for current pregnancy & 380 & $(34)$ \\
\hline \multicolumn{3}{|l|}{ Source of antenatal care service } \\
\hline \multicolumn{3}{|l|}{ Government medical sector } \\
\hline Hospital & 21 & $(1.9)$ \\
\hline Health center/station & 255 & $(22.8)$ \\
\hline Health post & 86 & $(24.7)$ \\
\hline Other public health areas & 2 & $(0.22)$ \\
\hline \multicolumn{3}{|l|}{ Private medical sector } \\
\hline Hospital & 10 & $(0.9)$ \\
\hline Clinic & 13 & $(1.2)$ \\
\hline NGO medical sector & 6 & $(0.5)$ \\
\hline Other places & 1 & $(0.05)$ \\
\hline \multicolumn{3}{|l|}{ Antenatal care provider } \\
\hline Doctor & 37 & $(4.7)$ \\
\hline Health officer & 14 & $(1.8)$ \\
\hline Midwife & 64 & $(8.2)$ \\
\hline Health extension worker & 101 & (13) \\
\hline Traditional attendant & 2 & $(0.3)$ \\
\hline \multicolumn{3}{|l|}{ Pregnancy trimester ANC } \\
\hline First & 162 & $(39.4)$ \\
\hline Second & 199 & $(48.1)$ \\
\hline Third & 51 & (12.3) \\
\hline Not remember/don't know & 1 & $(0.3)$ \\
\hline \multicolumn{3}{|l|}{ Number of antenatal visits } \\
\hline $1-5$ & 350 & (85) \\
\hline
\end{tabular}

NGO: Non-governmental organization; ANC: Antenatal Care 


\begin{tabular}{|lcc|}
\hline & $\mathbf{n}$ & (\%) \\
\hline $6-10$ & 57 & $(13.8)$ \\
\hline $11-15$ & 1 & $(0.2)$ \\
\hline Not remember/don't know & 4 & $(1)$ \\
\hline NGO: Non-governmental organization; ANC: Antenatal Care \\
\hline
\end{tabular}

\section{Drug use during pregnancy}

As described in Table 4, about 10,29 (91.8\%) of surveyed pregnant reported they had taken at least one prescription drug. Among those pregnant women, 263 (34\%) consumed iron folate. More than seven types of pharmacological classes of drugs were prescribed to pregnant women (Fig. 1). Concerning the non-supplementary drugs anthelmintic, antibiotics, and antimalarial drugs were taken by $15.3,6 \%$, and $1.7 \%$ of pregnant women, respectively. Aspirin $0.31 \%$ was the only analgesics reported drug by participants. About $362(46.5 \%)$ of pregnant had taken tetanus vaccination, thus nearly $339(43.5 \%)$ of them were taken less than four times. The majority reason to take was fever during pregnancy pregnant. 
Table 4

Drug utilization pattern among pregnant women age 15-49, Ethiopia DHS 2016

\begin{tabular}{|c|c|c|c|}
\hline Drug category & Name & $\mathbf{N}$ & $\%$ \\
\hline \multirow[t]{6}{*}{ Antimalarial drugs } & IPTp-SP & 3 & $(0.26)$ \\
\hline & Chloroquine & 1 & $(0.01)$ \\
\hline & Quinine & 5 & $(0.42)$ \\
\hline & Combination with artemisinin & 6 & $(0.5)$ \\
\hline & Artesunate & 2 & $(0.18)$ \\
\hline & Other anti-malarial & 3 & $(0.28)$ \\
\hline \multirow[t]{3}{*}{ Antibiotic drugs } & \multirow[t]{2}{*}{ Pill/syrup } & 15 & $(1)$ \\
\hline & & 48 & $(4)$ \\
\hline & Injection & 51 & $(1)$ \\
\hline Analgesics/antiplatelet & Aspirin & 4 & $(0.31)$ \\
\hline Antiemetics & Antimotility & 1 & $(0.01)$ \\
\hline Supplementary & Iron, zinc & 263 & (34) \\
\hline Anthelmintic & N/A & 171 & $(15.3)$ \\
\hline \multirow[t]{2}{*}{ Other drugs } & Other taken & 2 & $(0.19)$ \\
\hline & Other injection (non-antibiotic) & 1 & $(0.04)$ \\
\hline \multirow[t]{8}{*}{ Number of tetanus injection } & Never received & 397 & $(51)$ \\
\hline & 1 & 73 & $(9.4)$ \\
\hline & 2 & 134 & $(17.3)$ \\
\hline & 3 & 131 & $(16.9)$ \\
\hline & 4 & 15 & (1.9) \\
\hline & 5 & 9 & $(1.1)$ \\
\hline & 6 & 1 & $(0.1)$ \\
\hline & Don't know & 20 & $(2.6)$ \\
\hline
\end{tabular}




\section{Associated factors with medication use among pregnant women}

Table 5 shows the multivariate logistic regression estimation of factors associated with drug use during pregnancy. Variables such as age, economic status, plan of pregnancy, former childbirth before a year and five years, and the month of pregnancy when first antenatal care was received. 
Table 5

Associated factors with medication use among Ethiopian pregnant women aged 15-19 years, EDHS 2016

\begin{tabular}{|c|c|c|c|c|}
\hline \multirow[t]{2}{*}{ Respondent characteristics } & \multicolumn{2}{|c|}{ Drug use during pregnancy } & \multirow[t]{2}{*}{ Adjusted OR (95\% Cl) } & \multirow[t]{2}{*}{ p-value } \\
\hline & $\mathrm{n}$ & (\%) & & \\
\hline \multicolumn{5}{|l|}{ Age (years) } \\
\hline $15-19$ & 96 & $(9.3)$ & 1.00 & \\
\hline $20-34$ & 781 & $(75.9)$ & $0.649(0.147-2.861)$ & 0.568 \\
\hline $35-49$ & 153 & $(14.8)$ & $0.35(0.069-1.772)$ & 0.038 \\
\hline \multicolumn{5}{|l|}{ Wealth status } \\
\hline Poorest & 234 & (23) & 1.00 & \\
\hline Poorer & 232 & $(22)$ & $0.63(0.308-0.941)$ & 0.113 \\
\hline Middle & 177 & (17) & $0.47(0.218-1.628)$ & 0.003 \\
\hline Richer & 190 & (18) & $2.69(1.803-1.472)$ & 0.065 \\
\hline Richest & 197 & (19) & $3.75(5.335-0.928)$ & 0.123 \\
\hline \multicolumn{5}{|l|}{ Plan of pregnancy } \\
\hline Needed & 738 & (71.7) & 1.00 & \\
\hline Accepted later & 192 & $(18.7)$ & $0.458(0.21-1)$ & 0.001 \\
\hline Never accepted & 99 & $(9.6)$ & $1.257(0.324-4.876)$ & 0.616 \\
\hline \multicolumn{5}{|l|}{ Trimester } \\
\hline First trimester & 229 & $(22.2)$ & 1.00 & \\
\hline Second trimester & 405 & (39.3) & $0.778(0.269-2.248)$ & 0.67 \\
\hline Third trimester & 396 & $(38.5)$ & $0.507(0.172-1.493)$ & 0.069 \\
\hline \multicolumn{5}{|l|}{ Births in the past year } \\
\hline No births & 981 & $(95.3)$ & 1.00 & \\
\hline 1 & 48 & $(4.7)$ & $6.197(1.25-30.724)$ & 0.018 \\
\hline 2 & 0 & $(0)$ & 1.000 & 0.968 \\
\hline \multicolumn{5}{|l|}{ Births in the last five years } \\
\hline No births & 362 & $(35.1)$ & 1.00 & \\
\hline 1 & 429 & $(41.6)$ & $0.46(10.054-3.901)$ & $<0.000$ \\
\hline
\end{tabular}




\begin{tabular}{|c|c|c|c|c|}
\hline \multirow[t]{2}{*}{ Respondent characteristics } & \multicolumn{2}{|c|}{ Drug use during pregnancy } & \multirow[t]{2}{*}{ Adjusted OR (95\% Cl) } & \multirow[t]{2}{*}{ p-value } \\
\hline & $\mathbf{n}$ & $(\%)$ & & \\
\hline 2 & 207 & $(20.1)$ & $0.612(0.065-5.786)$ & $<0.000$ \\
\hline 3 & 30 & $(2.9)$ & 1.000 & 0.211 \\
\hline 4 & 2 & $(0.2)$ & 1.000 & 0.635 \\
\hline \multicolumn{5}{|l|}{ Government medical sector } \\
\hline Hospital & 21 & $(5.7)$ & 1.000 & \\
\hline Health center/station & 257 & $(70.3)$ & $5.345(0.252-113.548)$ & 0.641 \\
\hline Health post & 85 & $(23.3)$ & $0.269(0.0145 .299)$ & 0.338 \\
\hline Other public health area & 3 & $(0.7)$ & 1.000 & 0.949 \\
\hline \multicolumn{5}{|l|}{ Antenatal care provider } \\
\hline skilled provider & 394 & $(99.4)$ & 1.000 & 0.179 \\
\hline Unskilled provider & 2 & $(0.6)$ & & \\
\hline \multicolumn{5}{|l|}{ Trimester of first ANC } \\
\hline First & 153 & $(39.4)$ & 1.000 & \\
\hline Second & 184 & $(47.3)$ & $0.066(0.005-0.892)$ & 0.015 \\
\hline Third & 51 & $(13.1)$ & 1.000 & 0.663 \\
\hline Not remember/don't know & 1 & $(0.3)$ & & \\
\hline \multicolumn{5}{|l|}{ Number of antenatal visits } \\
\hline $1-5$ & 328 & $(84.0)$ & 1.000 & \\
\hline $6-10$ & 57 & $(14.7)$ & $3.244(0.189-55.566)$ & 0.543 \\
\hline $11-15$ & 1 & $(0.1)$ & 1.000 & 0.834 \\
\hline Not remember/don't know & 4 & $(1.1)$ & 1.000 & 0.658 \\
\hline
\end{tabular}

Pregnant with age group of 35-49 years old used drugs less likely by $65 \%$ when compared to 15 to 19 years old $(\mathrm{OR}=0.35$ and $95 \% \mathrm{Cl}=0.069-1.772)$. The lowest income pregnant women were more likely to use drugs during their pregnancy period by $53 \%$ than middle income pregnant $(\mathrm{OR}=0.47$ and $95 \% \mathrm{Cl}=$ $0.218-1.628)$. Concerning the readiness of pregnancy, during the occurrence of unintended pregnancy; women utilize drug less likely by $54 \%$ than the planned pregnancy $(\mathrm{OR}=0.458$ and $95 \% \mathrm{Cl}=0.21-1.000)$. Even though a significant association was not observed in the trimester of pregnancy, a remarkable number $405(39.3 \%)$ and $396(38.5 \%)$ of mothers has been taken medications during the second and 
third trimester, respectively. Most (70.3\%) of drugs were prescribed from the health center in which almost all $(99.6 \%)$ of medications were prescribed by skilled providers.

Furthermore, women who gave at least one live birth before a year of the survey, most likely used the drug by 6 times $(\mathrm{OR}=6.197$ and $95 \% \mathrm{Cl}=1.25-30.724)$ than no births a past year. Likewise, women who had 2 live births took medications less likely by $39 \%$ than no births $(\mathrm{OR}=0.612$ and $95 \% \mathrm{Cl}=0.065-5.786)$ in the same year. Concerning the first timing of visiting the first ANC trimester, pregnant at the second trimester used medication less likely by $93 \%(\mathrm{OR}=0.066$ and $95 \% \mathrm{Cl}=0.005-0.892)$ than first-trimester pregnancy.

\section{Discussion}

Our study generated results from the Ethiopian demographic and health survey (EDHS) 2016 dataset. Utilizing the medications during pregnancy is critical since the safety of drug is uncertain nowadays. Avoiding, reducing the use of drugs during pregnancy are essential components in improving the health and welfare of the mother and their children [18]. Utilizing antenatal care has a remarkable advantage in the monitoring of drugs utilizing during the periods of pregnancy.

This study observed that the prevalence of using medication during pregnancy was around $91.8 \%$. Other similar studies were done in Ethiopian cities also supports the recent finding. For instance, the prevalence was $88 \%$ in Bahr Dar, Adigrat (88\%), and Harar (85\%). Similarly, higher in Addis Ababa (71\%) and lower than Nekemte (96\%). Comparing to other countries the percentage was higher than in the Netherlands [20], 65\% in the United Kingdom [21], and 56\% in Canada [22]. However, it is lower than 96\% in France [22] and $93 \%$ in Iceland [23].

The recent study revealed supplementary drugs took the largest proportion; thus, iron folate was mainly (34\%) prevalent. Among the non-supplementary drugs, anthelmintic was the commonly prescribed drug. The frequent use of these drugs (supplementary and anthelmintic) might be as they are the component of the antenatal care package. Similarly, antibiotics and antimalarial drugs were taken by 6 and $1.7 \%$ of pregnant women. All of the classes of drugs found in this study were included in ANC service components which are recommended by WHO as a supplement or preventive interventions [17]. Generally, it is possible to say that medication consumption is lower. However, the prevalence of utilization of supplements, malarial prevention, and anthelmintic is not enough yet in the country. For instance, "WHO recommends that moderate to high-risk areas for transmission of malaria in Africa, antimalarials such as IPEp-SP should be given to all pregnant during each ANC visits [17].

In Ethiopia, areas were categorized into three levels that around $75 \%$ of the country are stratified as unstable and endemic areas for transmissions of malaria $[24,25]$. Thus, the ministry of health $(\mathrm{MoH})$ policy specified the chemoprophylaxis with antimalaria during pregnancy. But, the weak implementation perceived with the recent study is also supported by Robert et al [26]. Concerning anthelmintic use, WHO recommends all pregnant should take anthelmintic since the second trimester in endemic areas $[17,18]$. In Ethiopia, several studies revealed the high prevalence of helminthic transmission among pregnant; $51 \%$ 
in Tigray [27], 41\% in Oromia [28], 31.5\% in Addis Ababa [29]. The present study observed only $15 \%$ of pregnant women had taken anthelmintic at the national level. This finding is similar to the 2000 to 2017 DHS survey, that covered 48 Soil-transmitted helminthiases (STH) endemic countries [30]. Results from this survey showed an average of $23 \%$ ( 16 million) pregnant were dewormed worldwide. This implies the prevention of parasitic infection was anticipated since Ethiopia has been marked as an endemic country. Enhancing the Antenatal care (ANC) utilization might help to increase the coverage. For instance, an African country Congo has dewormed about $86 \%$ of pregnant women using ANC channel, in the same survey year [30].

Pregnant aged from 35 to 45 has been taken medicines less likely when compared to younger pregnant women $\mathrm{P}=0.038,(\mathrm{OR}=0.35$ and $95 \% \mathrm{Cl}=0.069-1.772)$. This might be attributed to the that, older mothers may less likely to take medications due to afraid of side effects. The poorest mother had taken medications more likely by $53 \%(\mathrm{OR}=0.47$ and $95 \% \mathrm{Cl}=0.218-1.628)$ than the middle one. The possible reason might be related to their lower socio-economic status [21]. A lower living standard could expose them to various diseases due to reduced nutrient intake, lack of latrine access and utilization, etc. As a result, the probability of medication prescription might be higher [27]. Furthermore, women who wanted to conceive take medications more likely by $54 \%(\mathrm{OR}=0.458$ and $95 \% \mathrm{Cl}=0.21-1.000)$ than unintended pregnancy. A possible explanation for this may be, a mother who needed the pregnancy could give more care and attention. Consequently, they most likely utilize antenatal care services in which our analysis shows the most prevalent prescribed drugs were components of ANC services.

Although no significant association was observed with a month of pregnancy, a remarkable number 405 $(39.3 \%)$ and $396(38.5 \%)$ of pregnant has been taken at their second and third trimester, respectively. This finding is opposed to other studies done in Ethiopia. Hence, bedewi et al [15] revealed that almost half of the drugs were prescribed in the first trimester. Likewise, $42 \%$ of medication prescribed in the first trimester study done in Adigrat general hospital [11]. Moreover, concerning the first time of visiting the first ANC service, being pregnant in second trimester associated significantly to take medications $(P=$ 0.015). This implies the study participants in the present study less possibly vulnerable to the potential risk of medications. The teratogenous effect of the drug is high in first trimester due presence of organogenesis in the first three months is expected [31]. The other possible reason for prescription in second trimester is attributed to the WHO recommendation to start preventive chemotherapies such as antimalarial and anthelmintic after the first trimester [17].

Furthermore, the present study revealed women who gave at least one live birth before a year of the survey, were 6 times $(\mathrm{OR}=6.197$ and $95 \% \mathrm{Cl}=1.25-30.724)$ more likely to utilize medications than primigravida. This is in agreement with a study in Adigrat [11] and Bahir Dar city [13]. This may be attributed to the high risk of maternal complications since the pregnancy gap is very narrow. Likewise, the current study also observed the women who had 2 live births took medications less likely by $39 \%$ than no births $(\mathrm{OR}=0.612$ and $95 \% \mathrm{Cl}=0.065-5.786)$ in the same year. Our result illustrates that the utilization of medication during pregnancy is somehow per the WHO ANC service recommendations. However, the antenatal care coverage and utilization policy of Ethiopia needs to be implemented more [32].

Page 15/20 


\section{Limitation of the study}

The study has several limitations. Firstly, the taxological category (US-FDA risk classification) of drugs that specified under the "other types" of the drug is not considered. This is because the data obtained did not list the drug names. Secondly, the overall consumption of medications might be underestimated since the over-the-counter medicines were included not in the survey data. Moreover, the rationale for the prescription of medications for the maternal complications is not considered in our study. This might be a challenge whether the drugs were indicated per needed or not. Lastly, this study measured only the prescription pattern but not the outcome of the chemotherapy. So, the effectiveness of the treatments cannot be estimated in this study.

\section{Conclusion}

Supplemental drugs were prescribed commonly to pregnant women. Among non-supplemental drugs, anthelmintic were the majority. These drugs were found to be components of ANC service. Taking medications was significantly associated with respondent characteristics such as age, socio-economic status, plan of pregnancy number of gravidities, and antenatal care utilization. Yet, the prevalence of ANC utilization was lesser among pregnant women. A further detailed investigation is needed to explore the reasons why the utilization is minimal. Furthermore, policymakers should explore further to improve the medication use during pregnancy through the ANC channel.

\section{Abbreviations}

ANC: Antenatal Care Service; OR: Odds Ratio; US-FDA: United states Food and Drug Administration; WHO: World Health Organization; DHS: Demographic Health Survey; EDHS: Ethiopian Demographic Health Survey; STH: Soil-Transmitted Helminthiases; MoH: Ministry of Health, IPEp-SP: SulfadoxinePyrimethamine; NGO: Non-governmental organization; HSTP: Health Sector Transformation Plan, ICF: International Function of function

\section{Declarations}

\section{Acknowledgment}

We would like to thank DHS program office for their fantastic collaboration to provide dataset.

\section{Authors' contributions}

GA, obtained the dataset. GA, WA, and DT did a literature review, and drafted the manuscript. EMA, $H G$, and DG performed data analysis, reviewed and drafted the manuscript. GA and WA critically drafted and reviewed the manuscript. The manuscript has read and approved by all authors in this study 


\section{Competing interests}

None

\section{Funding}

None

\section{Availability of data and materials}

The dataset of the present study is available online in DHS program office site https://DHSprogram.com/Data

\section{Ethics approval and consent to participate}

Not Applicable

\section{Consent for publication}

Not applicable.

\section{References}

1. M. M. Lynch et al., "Making Decisions About Medication Use During Pregnancy: Implications for Communication Strategies," Matern. Child Health J., vol. 22, no. 1, pp. 92-100, Jan. 2018.

2. L. F. Gomez Arango, H. L. Barrett, L. K. Callaway, and M. D. Nitert, "Probiotics and Pregnancy," Curr. Diab. Rep., vol. 15, no. 1, p. 567, Jan. 2015.

3. Y. S. Briggs GG, Freeman RK, "Drugs in pregnancy and lactation: a reference guide to fetal and neonatal risk. Philadelphia," Wolters Kluwer/ Lippincott Williams Wilkins Heal.., 2012.

4. Y. C. Kaplan, "Drug use and/or exposure in pregnancy: Presence of risk versus quantity of risk," J. Turkish Ger. Gynecol. Assoc., vol. 16, no. 2, pp. 123-123, Jun. 2015.

5. L. M. Tierney, S. J. McPhee, and M. A. Papadakis, "Current Medical Diagnosis \& Treatment, 2006 (Current Medical Diagnosis and Treatment)," p. 1884, 2005.

6. M. Dawes and P. J. Chowienczyk, "Pharmacokinetics in pregnancy," Best Pract. Res. Clin. Obstet. Gynaecol., vol. 15, no. 6, pp. 819-826, Dec. 2001.

7. M. M. Costantine, "Physiologic and pharmacokinetic changes in pregnancy," Front. Pharmacol., vol. 5, Apr. 2014. 
8. S. E. Andrade et al., "Prescription drug use in pregnancy," Am. J. Obstet. Gynecol., vol. 191, no. 2, pp. 398-407, Aug. 2004.

9. A. Mohammed MA, Ahmed JH, Bushra W and HS., "Medications use among pregnant women in Ethiopia: A cross sectional study.," J. Appl. Pharm. Sci., vol.;3:116 - 23., 2013.

10. L. M. Yates and S. H. L. Thomas, "Prescribing medicines in pregnancy," Medicine (Baltimore)., vol. 44, no. 7, pp. 438-443, Jul. 2016.

11. N. M. Alema et al., "Patterns and determinants of prescribed drug use among pregnant women in Adigrat general hospital, northern Ethiopia: a cross-sectional study," BMC Pregnancy Childbirth, vol. 20, no. 1, pp. 1-9, 2020.

12. F. Asfaw, M. Bekele, S. Temam, and M. Kelel, "Drug utilization pattern during pregnancy in Nekemte referral hospital: a cross sectional study," Int. J. Sci. Reports, vol. 2, no. 8, p. 201, 2016.

13. C. Admasie, B. Wasie, and G. Abeje, "Determinants of prescribed drug use among pregnant women in Bahir Dar city administration, Northwest Ethiopia: A cross sectional study," BMC Pregnancy Childbirth, vol. 14, no. 1, 2014.

14. B. Kebede, T. Gedif, and A. Getachew, "Assessment of drug use among pregnant women in Addis Ababa, Ethiopia," Pharmacoepidemiol. Drug Saf., vol. 18, no. 6, pp. 462-468, 2009.

15. N. Bedewi, M. Sisay, and D. Edessa, "Drug utilization pattern among pregnant women attending maternal and child health clinic of tertiary hospital in eastern Ethiopia: Consideration of toxicological perspectives," BMC Res. Notes, pp. 1-7, 2018.

16. M. Belay, W. Kahaliw, and Z. Ergetie, "Assessment of drug utilization pattern during pregnancy in Adama.," Int. J. Pharm. Sci. Res., vol. 4, no. 5, pp. 1905-1911, 2013.

17. World Health Organization, "WHO recommendations on antenatal care for a positive pregnancy experience," 1981.

18. World Health Organization, "Guidelines for the identification and management of substance use and substance use disorders in pregnancy," 2013.

19. K. Kaewkiattikun, "Central Statistical Agency (CSA) [Ethiopia] and ICF. 2016. Ethiopia Demographic and Health Survey 2016. Addis Ababa, Ethiopia, and Rockville, Maryland, USA: CSA and ICF," 2017.

20. D. J.-V. Bakker MK, Jentink J, Vroom F, Van Den Berg PB, De Walle HE and Den Berg LT., "Maternal medicine: drug prescription patterns before, during, and after pregnancy for chronic, occasional, and pregnancy-related drugs in the Netherlands.: :.," Int J Gynecol Obs., vol. 113(5), pp. 559-68., 2006.

21. C. M. Sutcliffe AG, Wong IC, "Prescription drug use in pregnancy: more evidence of safety is needed.," Obs. Gynecol, vol. 18, pp. 87-92, 2012.

22. M. S. Daw JR, Hanley GE, Greyson DL, "Prescription drug use during pregnancy in developed countries: a systematic review," Pharmacoepidemiol Drug Saf, vol. 20(9), pp. 895-902, 2011.

23. A. G. Bertolini G, D’Amico R, Nardi D, Tinazzi A, “One model, several results: the paradox of the Hosmer Lemeshow goodness-of-fit test for the logistic regression model," J Epidemiol Biostat., vol. 5(4):251-3, 2000. 
24. "Guidelines for malaria epidemic prevention and control in Ethiopia.," Addis Ababa, Ethiopia:, 1999.

25. "National five year strategic plan for malaria control in Ethiopia," Addis Ababa, Ethiopia:, 2001.

26. R. D. Newman et al., "Burden of Malaria during Pregnancy in Areas of Stable and Unstable Transmission in Ethiopia during a Nonepidemic Year," vol. 30341, pp. 1765-1772, 2003.

27. M. G. Gebrehiwet, A. A. Medhaniye, and H. B. Alema, "Prevalence and associated factors of soil transmitted helminthes among pregnant women attending antenatal care in Maytsebri primary hospital, North Ethiopia," BMC Res. Notes, pp. 4-9, 2019.

28. Y. D. Getachew M, Tafess K, Zeynudin A, "Prevalence soil transmitted helminthiasis and malaria coinfection among pregnant women and risk factors in Gilgel Gibe dam Area, Southwest Ethiopia.," BMC Res Notes, vol. 6(263, pp. 1-7, 2013.

29. M. A. Derso A, Nibret E, "Prevalence of intestinal parasitic infections and associated risk factors among pregnant women attending antenatal care center at Felege Hiwot Referral Hospital, northwest Ethiopia," BMC Infect Dis, vol. 16, p. 530, 2016.

30. M. Bangert, P. Bancalari, D. Mupfasoni, A. Mikhailov, A. F. Gabrielli, and A. Montresor, "Provision of deworming intervention to pregnant women by antenatal services in countries endemic for soiltransmitted helminthiasis," PLoS Negl. Trop. Dis., vol. 13, no. 5, pp. 7-13, 2019.

31. "FDA Pregnancy Risk Information: An Update." [Online]. Available: https://www.drugs.com/ pregnancy-categories.html.

32. E. P. H. Institute, "Improving Antenatal Care Services Utilization in Ethiopia Full Report," no. June, 2016.

\section{Figures}




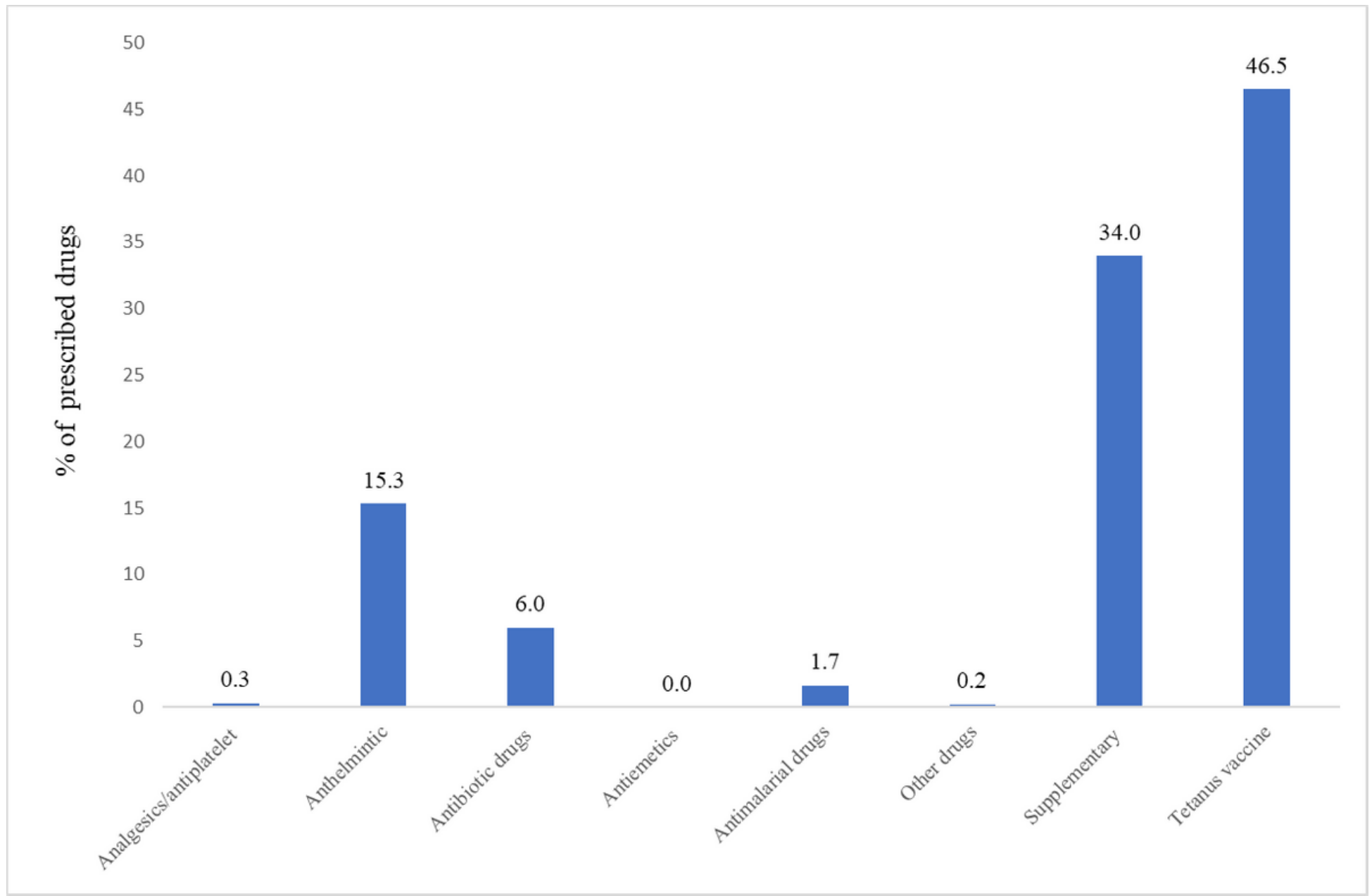

Figure 1

Drug category distribution among pregnant women in Ethiopia, EDHS 2016 